\title{
fTELLIE \\ Modos de vida ribeirinho na comunidade Foz do Rio Mazagão - Mazagão (AP/Brasil)
}

\section{Modo de vida a las orillas de la Foz del Rio Mazagão Mazagão - Mazagão (AP/Brasil)}

\author{
Modes de vie riverains dans la communauté de Foz do Rio \\ Mazagão - Mazagão (Amapá/Brésil)
}

\author{
Roni Mayer Lomba \\ Universidade Federal do Amapá. \\ ronimayer@hotmail.com \\ Meg Briane da Silva Fonseca \\ Universidade Federal do Amapá \\ megfonseca2010@hotmail.com
}

\begin{abstract}
Resumo
A comunidade ribeirinha Foz do Rio Mazagão - situa-se no município de Mazagão no Estado do Amapá. Sua formação está relacionada ao período de escravidão, no qual escravos fugitivos da Vila de Mazagão, no período colonial, ali resistiram. Seus modos de vida tratam por atividades tradicionais repassados pelas gerações, como a pesca artesanal, manejo do açaí e produtos madeireiros. O objetivo da pesquisa foi analisar a reprodução dos modos de vida na comunidade e seus dilemas. A metodologia utilizada compõe-se pela revisão bibliográfica e por entrevistas qualitativas com moradores da localidade (mais velhos, lideranças políticas e outros) para a compreensão da realidade local. Os resultados apontam a carência de políticas públicas básicas na comunidade como acesso à saúde, à educação e à eletricidade, o que, no entanto, não eliminou a organização política local em busca de melhores condições de vida e acesso aos direitos civis.
\end{abstract}

Palavras-chave: Foz do Rio Mazagão; modo de vida ribeirinho; comunidade tradicional.

\section{Resumen}

La comunidad a orillas de la Foz del Río Mazagão - se encuentra en el municipio de Mazagão en el estado de Amapá. Su creacion está relacionada con el período de la esclavitud, en la que los esclavos fugitivos de Mazagão resistieron en la Foz del rio Mazagão durante el período colonial. Ellos vivían conservando las actividades primarias tradicionales que eran transmitidas de generación en generación, la pesca artesanal, la colecta de açai y derivados de la madera. El objetivo de la investigación fue analizar la reproducción de los modos de vida de la comunidad y sus dificultades. La metodología utilizada según los métodos de revisión literaria y entrevistas cualitativas a los residentes locales (A las 
personas más antiguas, líderes políticos entre otros) para con ello poder entender la realidad local. Los resultados indican, la falta de política pública básica en la comunidad, como el acceso a la salud, la educación y la electricidad, sin embargo eso no hizo que la organización política de la localidad dejara de buscara mejoras en las condiciones de vida y del acceso a los derechos civiles.

Palabras clave: Foz del Río Mazagão; forma de vida ribera; comunidad tradicional.

\section{Résumé}

La communauté riveraine de Foz do Rio Mazagão est située dans le municipe de Mazagão, dans l'État d'Amapá au Brésil. Sa formation est liée à la période de l'esclavage : durant l'époque coloniale, les esclaves fugitifs de la Vila de Mazagão y résistèrent. Leurs modes de vies se composent d'activités traditionnelles transmises de génération en génération comme la pêche artisanale, la gestion de l'açaí et celle des produits forestiers. L'objectif de cette recherche est d'analyser la reproduction des modes de vie dans la communauté et ses dilemmes. La méthodologie utilisée fut la révision bibliographique et la réalisation d'entretiens qualitatifs avec les habitants de la localité (les anciens, les leaders politiques et d'autres) afin de mieux comprendre la réalité locale. Les résultats montrent la carence de politiques publiques de base dans la communauté comme l'accès à la santé, à l'éducation et à l'électricité. Cela n'a cependant pas affaiblit l'organisation politique locale, qui cherche de meilleures conditions de vie et l'accès aux droits civils.

Mots-clefs: Foz do Rio Mazagão ; mode de vie riverain ; communauté traditionnelle.

\section{Introdução}

Esse artigo é uma análise sobre os modos de vida dos moradores da Comunidade Foz do Rio Mazagão, as transformações no espaço rural e dos modos de produção, os problemas e anseios vividos pela comunidade. Os colaboradores da pesquisa - moradores da Comunidade Foz do Rio Mazagão - situa-se no município de Mazagão-AP, composta por 150 famílias que totalizam 936 habitantes. O local ocupa a área distribuída ao longo das duas margens do rio Mazagão e dos igarapés Espinhel, Mutuacá e Igarapé Grande.

$\mathrm{O}$ estudo realizado trata-se de uma pesquisa qualitativa, visto que se analisou o modo de vida a partir de trabalhos a campo mais densos, o que permitiram a coleta de informações que caracterizam o conjunto da comunidade. Utilizamos como método o materialismo histórico-dialético, na busca por refletir sobre as transformações sociais e econômicas no tempo e no espaço pela concepção de comunidade inserida na luta social de classes.

O materialismo histórico-dialético, porém, não é suficiente para compreender a organização tradicional, culturas e simbologias da comunidade. Por isso, recorremos também a busca da interpretação humanista para analisar outros fenômenos além das lutas de classe. Em termos de procedimentos para a efetivação da pesquisa foram levantadas fontes bibliográficas sobre o município de Mazagão e da comunidade estudada, realizadas atividades de campo como entrevistas com moradores antigos, líderes comunitários e religiosos, associações das mulheres extrativistas e associação de moradores. 
Esta investigação corresponde a uma leitura particular sobre o modo de vida da comunidade ribeirinha Foz do Rio Mazagão, realizando uma abordagem sobre a definição da categoria modo de vida nas Ciências Humanas e o quanto a produção do espaço e o sistema capitalista transformam a sociedade.

\section{Modos de vida e a formação da comunidade ribeirinha Foz do Rio Mazagão}

O termo modo de vida já fora tratado nas Ciências Humanas sob o contexto de "gênero de vida", que segundo La Blache (2005, p.2), "implica em uma ação metódica e contínua, que age fortemente sobre a natureza ou, para falar como geógrafo, sobre a fisionomia das áreas". Para Sorre (2003, p.140), o gênero de vida significa, "um conjunto coletivo de atividades transmitidas e consolidadas pela tradição, graças às quais um grupo humano assegura sua existência em um meio determinado”. Moraes (1994) ao analisar esses conceitos, supõe o homem como um hóspede que se adapta ao meio que o envolve, criando em acervo de técnicas, hábitos, usos e costumes. Este conjunto de técnicas e costumes representa o gênero de vida.

Marques (1994, p.17) refere-se ao modo de vida como um conjunto de práticas cotidianas desenvolvidas por um determinado grupo social.

[...] Corresponde à forma de um determinado grupo social manifestar sua
vida. Essas práticas cotidianas decorrem da história e da posição que o
grupo ocupa na sociedade e da forma específica que assegura a sua
reprodução social. [...] os hábitos e preferências de um grupo são
expressos por intermédio de um conjunto constituído de objetos pelos
meios de sustento, vestimenta, habitação, instrumentos e armas. [...] Seus
hábitos se tornam ritos, reforçados por crenças e superstições
(MARQUES, 1994, pag.17).

A mesma autora define que o modo de vida constitui um conjunto mais ou menos coordenado de atividades espirituais e materiais consolidado pela tradição. Um conjunto de técnicas, de vida em sociedade, de energia, de produção e transformação da matéria-prima é quem assegura a permanência do grupo ao meio. Contudo, nessa vida coletiva, o conjunto de técnicas que garantem os meios de sustento, habitação, vestimentas, pode sofrer mudanças. Fatores internos e externos como crescimento populacional, instrumentos e técnicas modernas, contato com outros povos, diferenciação profissional, divisão do trabalho, propriedade privada da terra, circulação de capital e mercadorias podem levar às transformações no modo de existência.

Com a expansão da propriedade privada, poucas sociedades rurais, especificamente, as ribeirinhas, conseguem manter parte desse modo tradicional de viver. $\mathrm{O}$ avanço das técnicas, a presença do capital, a troca e a venda de mercadorias, a mercantilização da terra, acabam ocupando a vida rural, modificando seu modo de vida. Carlos (1994) e Suzuki (1996) apontam que a difusão do mundo da mercadoria desagrega o modo de vida, construindo "o novo", em que as relações passam a ser mediatizadas pelo mercado e pela mercadoria. 
O mundo da mercadoria invade a vida das pessoas e tudo se estabelece numa cadeia de troca e venda. Com a expansão do capital no campo, as relações sociais ganham contornos mais abstratos. As festas comunitárias, por exemplo, que marcam a vida das pessoas, acabam ganhando novos sentidos. Elas deixam de ser comunitárias e passam a ser mercantis. As relações de vizinhança, também perdem o sentido de apoio e ajuda. No meio rural, é frequente a presença de um morador na casa de outro como forma de cortesia, motivos religiosos, de ajuda mútua, parentesco entre outros. Com a expansão da propriedade privada, os indivíduos ampliam o individualismo e acabam se isolando, tornando-se indiferentes aos outros.

Inicialmente, trataremos da origem da comunidade, por meio dos dados históricos que permitiram compreender a conformação populacional mais antiga de Mazagão e, em particular, do sistema ribeirinho deste município, pela bacia do rio Mazagão (RABELO, 2003). No passado, o rio Mazagão recebia o nome de rio Mutuacá. Ele foi escolhido por Mendonça Furtado - primeiro Governador do GrãoPará e Maranhão - para adensar a presença portuguesa na parte Norte da Amazônia.

Tendo com referência o trabalho de Vidal (2008), a colonização do município de Mazagão começou no século XVIII, no período em que a Coroa Portuguesa lutava para manter seu controle sobre os territórios amazônicos na porção Norte. Durante o período colonial, o território do Amapá, pertencente ao Grão-Pará - região que inclui os Estados atuais do Pará e Amapá - era uma região de constantes disputas por franceses, ingleses, holandeses, espanhóis e portugueses. Para manter o domínio sobre a região, os portugueses procuravam estabelecer uma presença militar no Norte do rio Amazonas, construindo fortalezas na foz deste rio e prevenindo invasões vindas do Oeste.

A Coroa Portuguesa também desejava povoar a região com cidadãos portugueses como medida adicional de segurança. Em particular, o Estado enviou oficiais para identificar uma região com a finalidade de construir uma estrutura urbana capaz de abrigar residentes de uma colônia portuguesa evacuada, localizada no Norte da África, expulsa pelos Mouros, (atual Marrocos), mais precisamente a cidade de El Jadida.

A colônia original na África foi fundada em 1513. A cidade era na realidade uma fortaleza cercada por uma praça, encabeçada por uma igreja ornada; foi construída no período inicial da colonização portuguesa, para servir de suporte náutico a viagens para a Índia, pela rota do Cabo. Pelo abandono português, essas colônias dominadas na África se tornaram vulneráveis a ataques. Em 1769, os Mouros invadiram a praça e quase destruíram a cidade.

A Coroa portuguesa não mais interessada em investir recursos na região, desativou a cidade e transferiu as famílias da colônia. Em setembro de 1769, o capitão Inácio de Castro Moraes Sarmento foi designado pelo governador Ataíde Teive a demarcar, às margens do rio Mutuacá, um sítio para refundação de Mazagão no lugar 
da antiga missão jesuítica de Santa Ana. Nos estudos de Lima (2005), registra-se um transporte de 340 famílias ou 1.022 pessoas. Para receber toda essa população, edificou-se a Vila Mazagão Amazônica, na margem esquerda do rio Mutuacá, onde logo foram assentadas 163 famílias: sendo os primeiros habitantes 114 brancos e 103 escravos, que se transformaram nos primeiros agricultores da região.

No primeiro ano, a manutenção das famílias de Nova Mazagão era subsidiada pela Coroa portuguesa. $\mathrm{O}$ abastecimento era assegurado por Belém, e às vezes, por Macapá, estocando os mantimentos no armazém de Nova Mazagão. A partir de 1773, as famílias instaladas na vila foram obrigadas a produzir suas próprias condições de sobrevivência. Para isso, o governador do Grão-Pará ordenou que os mazaganenses plantassem arroz e que os escravos africanos entregues a cada família abandonem os serviços domésticos e dediquem-se, exclusivamente, aos trabalhos agrícolas.

No entanto, os residentes não conheciam o clima, as potencialidades agrícolas e nem as técnicas necessárias para o desenvolvimento da rizicultura. Essa dificuldade se deu também pela má qualidade da terra. "Ao contrário do que pensavam os portugueses, as terras nos arredores de Nova Mazagão são improdutivas" (VIDAL, 2008, pag. 178). O cultivo faliu em 1781, quando uma epidemia atingiu a colônia. Apesar dos esforços para controlar a doença, muitos colonos morreram durante o ano.

Os anos sucessivos até a independência do Brasil foram marcados pelo caos na região de Mazagão. Depois da epidemia, muitos portugueses, escravos e índios migraram de Nova Mazagão para cidades maiores e para outros lugares nas redondezas. As fugas tornaram-se frequentes entre os índios, sendo que muitos escravos africanos permaneceram na Vila. A estes, poucas opções havia, pois não conheciam a geografia da região, dificultando a organização coletiva das fugas. No entanto, o declínio econômico e de povoamento de Mazagão gerou certo isolamento ou distanciamento de outros núcleos urbanos, favorecendo a proteção contra a condição de escravos.

$\mathrm{Na}$ floresta de Mazagão, os neomazaganenses e os escravos fugidos estavam livres do controle do trabalho e adaptaram-se aos meios de vida dos caboclos e dos indígenas da região. Estes refugiados provavelmente também tiveram contato com outros grupos. Em 1782, o novo governador do Grão-Pará, Tello de Menezes, informou Lisboa sobre a gravidade da situação. Um ano depois, a Coroa portuguesa concedeu a liberdade requisitada pelas famílias que ainda viviam em Nova Mazagão, permitindo que elas decidissem seu destino. A liberdade concedida na realidade serviu para mascarar o fracasso da construção da vila e a intenção da Coroa em se retirar de Mazagão (VIDAL, 2008).

Esse ano foi marcado pelo término da refundação de Mazagão na Amazônia. Por volta de 1915 e, baseados nos relatórios que expressavam a decadência da vila, ficou decidida a instalação desse burgo em uma área próxima ao furo "Beija-Flor", 
entre o rio Vila Nova e o Amazonas, denominada de Mazagão Novo ou Mazaganópolis (LIMA, 2005).

Segundo Steward (2008), escravos fugidos de Mazagão procuraram as redondezas da vila para se instalarem. Duas áreas que fazem fronteira com o rio Mutuacá, uma de terra e outra de várzea, foram ocupados por eles. As áreas abrangem atualmente a Vila do Carvão e a Comunidade Foz do Rio Mazagão. Quando Foz do Rio Mazagão foi fundada, por volta de 1800 (STEWARD, 2008), ela fazia parte da Vila Carvão. Pode-se dizer que a fundação dessas duas comunidades está interligada, visto que elas representavam nesse período apenas uma comunidade que recebia o nome de Carvão. Somente a partir de 1970 é que a área que corresponde à várzea passou a ser nominada de Comunidade Foz do Rio Mazagão, com padrões distintos de produção agrícola e organização social.

Baseando-se nos estudos realizados por Steward (2008), os primeiros moradores

dessas áreas eram das famílias Luz e Carmo. Eles estavam entre as famílias dos escravos trazidos pelos portugueses para Nova Mazagão. A história é confirmada por Maria da Luz, uma das moradoras mais antigas de Carvão. Segundo a entrevistada, seu bisavô, Antônio da Luz, recém-casado em Mazagão Velho (antiga Nova Mazagão), procurava um local para fazer o cultivo da mandioca e construir uma casa de farinha. Como a área em torno de Mazagão Velho estava muito ocupada, Antônio da Luz procurou um local fora da comunidade para executar essas atividades. Ele encontrou uma área grande de campo e juntamente com sua esposa ocupou o local. Ao observar o campo, encontrou dentro de um buraco uma pedra luminosa, que parecia com carvão.

Antônio da luz e sua esposa batizaram o nome do lugar de Carvão e no local onde encontraram a pedra instalaram uma casa de farinha e uma casa para morar. Com o tempo, o casal juntou membros de sua família que residiam ainda em Mazagão Velho e formou uma pequena vila. Segundo dona Maria Luz, seu bisavô teve 25 filhos, influenciando no crescimento do povoado.

Após a instalação da família Luz, a família Carmo, também vinda de Mazagão Velho, chegou à margem do igarapé Mutuacá. Este é um afluente do rio Mazagão, o que possibilita comunicação entre ambos. Tal área atualmente é nominada de Queimada. Neste lugar ainda reside um dos membros mais velhos da família Carmo - o senhor Nonato do Carmo. O mesmo afirmou desconhecer em que ano seus familiares vieram para a área, mas confirmou que sua família era original de Mazagão Velho e que na infância passava o mês de julho na Vila, visitando parentes e participando das festas religiosas de São Tiago. Contudo, ele desconheceu o motivo pelo qual os avós se estabeleceram na Queimada. Ele relatou que em meados de 1930, quando ainda era criança, existiam 25 casas entre os povoados de Carvão e foz de Mazagão. 


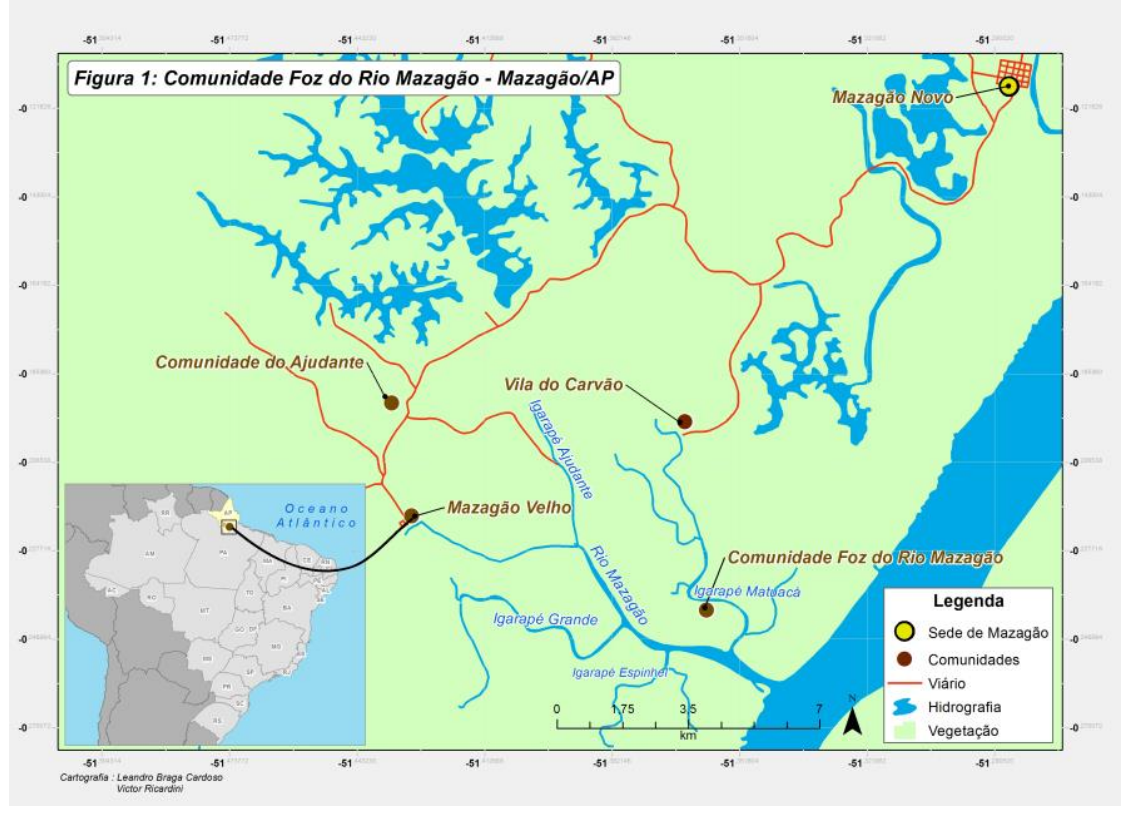

Figura 1 - Comunidade Foz do Rio Mazagão - AP

No ano de 1917, Monteiro da Silva, descendente de portugueses, se instalou na foz do rio Mazagão e construiu um grande comércio com 24 janelas que ficavam defrontes ao rio (Steward 2008). Este se apropriou de toda área que correspondia à várzea e de outras na terra firme. Sua instalação às margens do rio visava à exploração da seringa e de outros recursos naturais existente em toda a área da várzea neste período. Enquanto em muitas áreas da Amazônia a atividade extrativista do látex começava a enfraquecer, na várzea ela dominou a economia local e atraiu famílias, principalmente vindas das ilhas do Pará para o local.

Segundo os residentes, neste período existiam 11 famílias morando na área de várzea. Segundo Nonato Carmo, elas chegavam ao lugar em busca de melhores condições de sobrevivência, trabalhando para o proprietário das terras - Monteiro Silva. Neste período, os moradores viviam sob relações de aviamento. Este sistema consistia numa espécie de crédito não monetário, com base em relações clientelistas controlado por empresas exportadoras (GONÇALVES, 2001). A troca entre o comerciante (proprietário/empresário) e o produtor (seringueiro) dava-se geralmente sem a mediação da moeda, num sistema de escambo em que a moeda servia apenas como equivalente monetário.

Os moradores relatam que nesse período acordavam cedo para retirar látex. Muitos desconheciam as técnicas de extração do produto, mas aprendiam com a troca de experiências junto a outros moradores que executavam a tarefa há mais tempo. Os 
residentes trocavam látex e outros produtos por café, açúcar, farinha de mandioca, ferramentas agrícolas, tecidos, cachaça e outros junto às casas de aviamento. Os produtores combinavam ainda a atividade extrativista com a agricultura, pesca, caça e coleta de frutos e sementes.

Na década de 1960, quando a demanda de seringa diminuiu de forma considerável a exploração da madeira substituiu a extração desse produto tornando-se atividade principal nas áreas de várzea do rio Mutuacá. As principais espécies comercializadas eram cedro, samaúma, ucuuba, muiratinga, andiroba e mogno. No local do comércio foi construída uma serraria que recebia o nome de mazaganete. Muitos residentes trabalhavam como empregados na serraria, operando maquinaria para fazer tábuas das toras das madeiras.

Vários moradores também trabalhavam para a Brumasa - empresa madeireira holandesa, que possuía operações espalhadas na região. Os moradores extraíam madeira

das terras de várzea e vendiam de maneiras diferentes, ou seja, alguns continuavam a trocar madeira por mercadoria, enquanto outros recebiam dinheiro. Os navios da Brumasa entravam na foz de Mazagão para comprar toras de virola, andiroba e muiratinga. No rio Mutuacá, a madeira foi explorada durante 15 anos de forma intensiva e no final da década de 1980 uma parte dessas espécies se esgotou, gerando a saída das empresas na região.

Quando as empresas deixaram de executar suas atividades, muitas famílias locais, que aprenderam as técnicas de processar madeira e operar as serras, montaram suas próprias serrarias.

O povoamento das duas áreas e a evolução desses ambientes ocorre de formas diferentes. Enquanto na área de terra firme, o espaço ia ganhando formas urbanas, na área de várzea as formas permaneciam rurais. Com isso, na década de 1980, dois sistemas econômicos diferentes foram estabelecidos em Carvão e separou a comunidade em duas: Carvão e Mutuacá (Foz de Mazagão). Nas duas áreas, as famílias residentes sobreviviam participando de atividades comerciais diferentes para adquirir mercadorias e recolhendo alimentos das florestas, igarapés, rios e campos.

Na várzea, onde está Foz de Mazagão, os moradores mantinham um sistema misto de produção baseado na extração de madeira, açaí e camarão, todos vendidos localmente. Na terra firme, onde se localiza Carvão, as famílias produziam farinha para vender nos mercados da região, usando a várzea somente para pescar, caçar e coletar açaí. Os padrões de povoamento nas duas comunidades eram parecidos com a forma tradicional de povoamento da Amazônia (STEWARD, 2008), com uma pequena quantidade de famílias vivendo em núcleos espalhados.

Uma série de mudanças políticas, econômicas e sociais, que começou na década de 1980, transformou o cotidiano dos moradores, dentro de um período relativamente curto (STEWARD, 2008). Entre essas mudanças destaca-se a criação das 
associações que buscavam melhorar a qualidade de vida dos ribeirinhos pela independência socioeconômica e política.

Retomando a análise sobre modos de vida, concordamos com Marques (1994) ao afirmar que o modo de vida é um conjunto de práticas cotidianas desenvolvidas por um grupo, como forma de manifestar sua vida. Na comunidade estudada, os moradores expressam seu modo de vida por meio de um conjunto de técnicas, hábitos, usos e costumes num ritmo tradicional, regido pelos movimentos da natureza e numa relação contínua e íntima com o rio. Eles criaram suas formas de sobrevivência com o ambiente natural, que lhes oferece os obstáculos e as possibilidades. Sua população reproduz uma relação íntima com o meio natural circundante e dele retiram os elementos que viabilizam a sustentabilidade socioeconômica. O rio Mazagão é de suma importância, ele não é apenas um elemento na paisagem local, mas retrata algo que compõe o modo de ser e viver dos moradores.

O contato com o rio ocorre antes do nascer do sol. Por volta de $05 \mathrm{~h}$, as mulheres já estão no trapiche de suas casas carregando baldes com água para fazer o café e as outras atividades do dia. Os ribeirinhos consideram importante estarem reunidos nas principais refeições do dia e após o café da manhã os homens saem para a floresta, andando pela mata ou navegando em canoas. Os filhos maiores acompanham os pais no trabalho diário e as filhas ajudam as mães nos afazeres domésticos e na roça. Uma embarcação atraca nos trapiches das residências e leva as crianças à escola. Bem cedo também as mulheres alimentam os animais que transitam pelo terreiro.

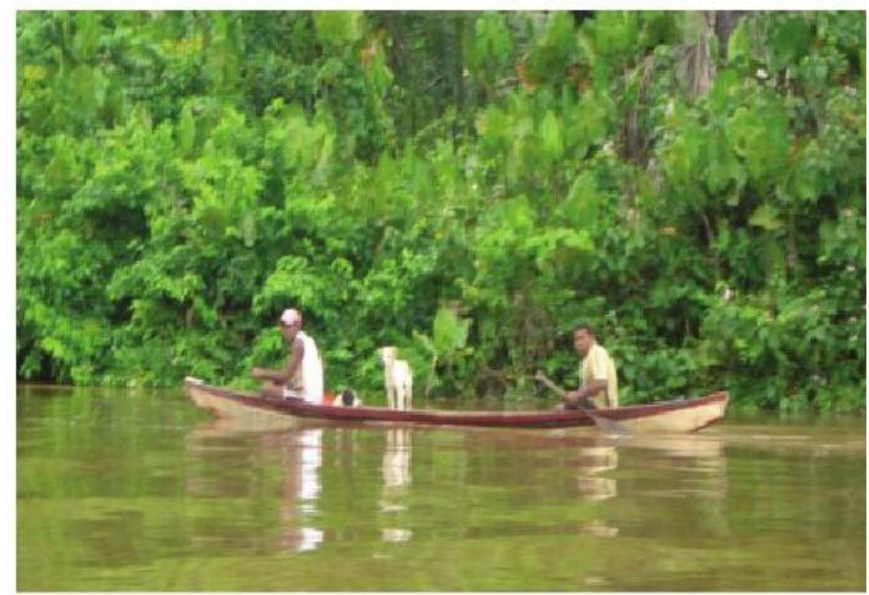

Figura 2: moradores a caminho do trabalho na mata Org: Lomba e Fonseca, 2011.

A alimentação dos moradores é uma combinação de açaí com peixe e camarão. Eles também consomem carne bovina, frango, farinha, arroz, feijão, enlatados, embutidos entre outros. O peixe, camarão e açaí são extraídos no próprio 
local. Os outros alimentos são comprados nos comércios da comunidade, na vila de Mazagão Velho e ainda no município de Santana. Eles também se alimentam de animais da floresta como paca, cutia, veado, porco-do-mato, tatu. A água consumida é retirada do próprio rio, porém, fervida antes do consumo.

$\mathrm{Na}$ paisagem local, as casas são construídas de madeira. Algumas se apresentam mais amplas e com certo conforto, contendo sala, cozinha, banheiros e vários quartos, outras mais simples, com apenas três ou quatro cômodos, cobertas com palha. Observamos a existência de objetos característicos do meio urbano, como: freezer, geladeira, televisão, ferro de passar roupa, guarda-roupa, DVD, liquidificador, fogão a gás, camas e até computador. Ainda é notória a existência de fogão à lenha e de redes de dormir.


Figuras 3 e 4: Modelos de residência na Comunidade (padrão mais elevado a esquerda e mais simples a direita)

Org: Lomba e Fonseca, 2011.

O fogão à lenha representa outra temporalidade e uma forma de existência típica de comunidades tradicionais, os ribeirinhos, por exemplo, relatam que o alimento fica mais saboroso e que o sono na rede é mais confortável. O fogão a gás, em muitos casos, serve para o preparo de alimentos em caráter emergencial. Em frente das residências ficam ancoradas as embarcações. Algumas bem simples como canoas de madeira e outras mais modernas, como voadeiras de alumínio, barcos de corrida, catraios etc. São os meios de transporte utilizados para locomoverem-se no rio. 

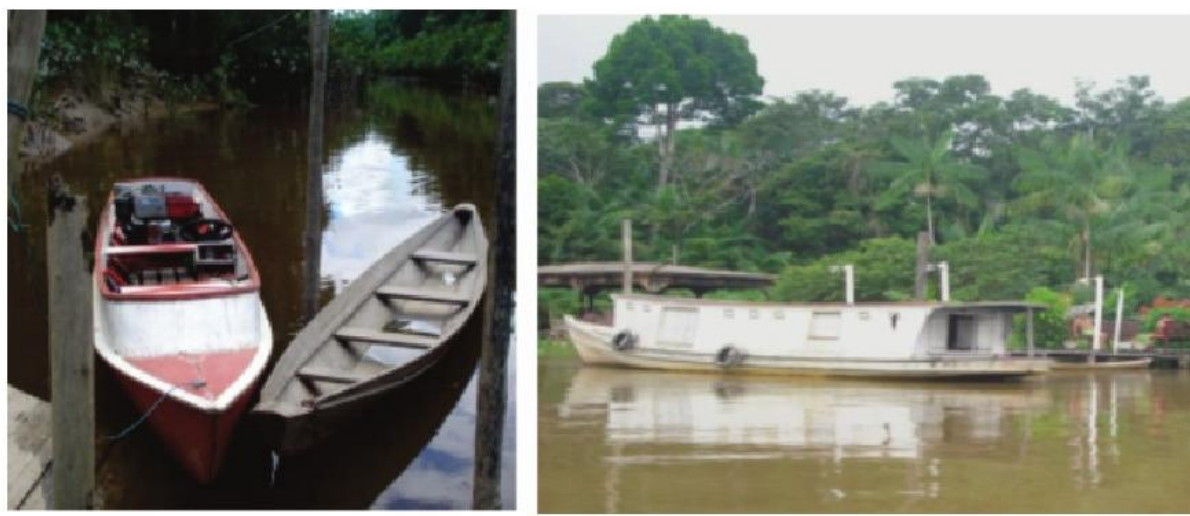

Figura 5 e 6: principais meios de transporte utilizado pelos ribeirinhos: a esquerda, barco a motor e canoa a remo e a direita, o catraio. Org: Lomba e Fonseca, 2011

Antigamente, os moradores produziam o vinho do açaí utilizando materiais rústicos como o alguidar ou gamela, caroceira e peneira. Afirmavam que o açaí elaborado dessa maneira era mais saboroso e não apresentava borra. Atualmente, com a disponibilidade de energia elétrica, as famílias adquiriram batedeiras elétricas de açaí e não utilizam mais a forma rudimentar. Segundo os moradores, é mais rápido fazer o vinho na máquina, porém, dessa forma, a polpa apresenta borra e é menos saboroso.

$\mathrm{Na}$ comunidade, apenas um único membro mantém o uso dos instrumentos rústicos. Em todas as residências existem energia elétrica e os moradores não pagam pelo consumo da mesma (a energia é produzida por geradores a diesel e o combustível é concedido pelo Estado). Na ausência de energia, eles utilizam lamparinas (pequena lata contendo querosene e um chumaço de algodão para acender o fogo) ou então velas de cera.

Cada família possui dois ou mais celulares para se comunicar com os outros moradores. Até 2005, quando não havia sinal de telefonia na área, apenas três residências possuíam os aparelhos. O sinal do aparelho celular chegava por uma antena conectada constantemente a ele. Quando os outros moradores precisavam ligar, iam a uma das residências e pagavam o valor correspondente a $\mathrm{R} \$ 1,00$ por minuto. Em 2007, foi instalada uma torre da operadora VIVO na vila de Mazagão Velho, cujo sinal abrangeu também a área. A inauguração da torre foi motivo de muita alegria para os ribeirinhos, sendo comentado pelos mesmos. $\mathrm{O}$ evento de inauguração do sinal fora comemorado por autoridades locais juntamente com os técnicos da operadora. A partir disso, os moradores logo adquiriram aparelhos celulares, mostrando um objeto útil para a comunidade.

Outra informação relevante coletada junto aos moradores foi sobre os conhecimentos acerca das plantas utilizadas como medicamentos, alimentos, entre outros. Dona Zuleide Azevedo é uma moradora antiga da comunidade e possui o ofício 
de parteira, sendo considerada pelos moradores como curandeira. Ela nos relata que já fez mais de 30 partos e que faz tratamento de fertilidade para as mulheres que não conseguem engravidar e para aquelas que estão em risco gestacional. Muitos moradores procuram dona Zuleide para benzer os filhos contra quebranto e susto. Ela conta que no lugar existe muita assombração e quando a pessoa extrapola os limites da natureza passa a sofrer de "caruara".

A caruara é um tipo de enfermidade sem causa aparente, que provoca dor reumática e paralisa as articulações. Para acabar com o feitiço, ela faz defumação com folhas de aningá nas pernas do enfermo. Trata-se de uma tradição popular que teve apelo maior no passado, mas que no momento convive com a descrença daqueles que não acreditam nesse tipo de conhecimento na comunidade. Muitos residentes relatam desacreditar no saber popular, nas assombrações e em casos de enfermidades, preferem procurar atendimento médico. Até mesmo a crença popular de que as mulheres poderiam engravidar do boto, enfeitiçadas ao se banharem no rio, é algo já bastante desacreditado.

No que se referem à relação familiar, os pais são bastante rígidos no que tange ao respeito dos mais novos em relação mais velhos. Os filhos mais velhos e casados respeitam seus pais assim como os mais novos. Há um ritual tradicional de pedido de bênção dos filhos para os pais quando chegam e quando saem de casa. Na comunidade todos os moradores cumprimentam as pessoas que vão às suas casas, saudando-lhes com "bom dia!", "boa tarde!" e "boa noite!" (dependendo do horário da visita), sempre oferecem café e servem algo para a visita comer.

Tanto os adultos como as crianças são receptivas. Quando há uma visita em casa, eles demonstram grande satisfação em receber. Sobre a educação escolar, as famílias têm participação ativa. Tanto para os pais, como para os alunos, o professor é valorizado e muito respeitado. É comum no meio rural a evasão escolar, por desde cedo terem que ajudar os pais no trabalho, contudo, em foz de Mazagão, as crianças vão à escola com frequência, pois, consideram o estudo importante para a formação. Por conta disso, grande parte dos filhos dos ribeirinhos já concluiu o Ensino Médio, sendo que alguns estão matriculados no Ensino Superior.

$\mathrm{Na}$ comunidade existe uma igreja católica e outra protestante. $\mathrm{Na}$ igreja protestante são realizados cultos aos domingos, quartas e sextas. Um grupo pequeno de moradores faz parte desta denominação religiosa. A igreja católica foi fundada em 15 de dezembro de 1977, inaugurada por Dom José Maritano, e construída pelos próprios moradores. No início, o prédio era de madeira e coberta com palha. Recentemente, a comunidade construiu uma nova capela e denominaram-na de Nossa Senhora de Nazaré, coberta com telhas. Ela é comandada por dois líderes religiosos. No mês de outubro, a igreja católica realiza a procissão de Nossa Senhora de Nazaré e um bingo dançante. $\mathrm{O}$ evento tornou-se bastante popular e atrai pessoas das comunidades 
vizinhas. Além deste evento, a comunidade realiza o festival do açaí, na intenção de valorizar a cultura local e a produção extrativista.

Há dez anos, as festas eram mais frequentes no lugar. Os residentes faziam festas em homenagem a santos ou em comemoração a aniversários. Nestas, o dono da casa oferecia comida e bebida e a festa acontecia durante toda a noite, terminando ao amanhecer. Hoje, nas festas de aniversário, os convidados devem comprar a bebida que é vendida pelo anfitrião. O senhor Juraci Azevedo reclama: "A gente acaba pagando a festa de quem está aniversariando".

Seu Juraci Azevedo lembra com nostalgia de um tempo em que no verão eram promovidos torneios de futebol em campos que existiam atrás das casas de alguns moradores. Todo final de semana escolhia-se uma casa para fazer o jogo. Em frente à casa escolhida ficavam aportadas as embarcações. Eles reclamam que nos dias atuais, os torneios já não acontecem. Cada ribeirinho fica na sua casa e alguns passam o domingo na lida.

Nos últimos anos, a comunidade se organizou e criou as associações. A criação das associações foi incentivada por alguns moradores, dentre eles: Juraci Azevedo, Goreth Azevedo e Aurélio Henrique. Dentre elas apontamos a Ampafoz (Associação das Mulheres Produtoras de foz de Mazagão) e a Aaflomaza (Associação Agroflorestal Baixo Amazonas) as duas associações têm alcançado recursos que auxiliam os ribeirinhos na produção do açaí e do camarão. A Aaflomaza conseguiu empréstimos junto ao Banco da Amazônia, financiando os ribeirinhos a comprarem embarcações e outros instrumentos de trabalhos que ajudassem na atividade extrativista.

A associação das mulheres recebe apoio das pastorais e ajuda as mulheres sobre formas preventivas de gravidez, doenças, alimentação de recém-nascidos com a doação de suprimento alimentar, realização de cursos sobre hábitos de higiene, culinária, artesanato e para a produção sustentável do açaí e camarão, entre outros. Sobre o fato de os ribeirinhos terem se organizado socialmente, podemos afirmar que o surgimento das associações contribuiu para a melhoria na qualidade de vida dos moradores, inserção das mulheres na atividade extrativista do camarão e aquisição de bens materiais e ferramentas para o desenvolvimento das atividades econômicas.

As atividades econômicas existentes na comunidade são caracterizadas por padrões primitivos de subsistência, predominando o uso da mão de obra familiar e sem a presença de técnicas modernas de produção. Dentre essas atividades é notória a relevância do extrativismo da pesca de peixe e camarão, extração de açaí e exploração madeireira. Na pesca artesanal do camarão e do peixe os ribeirinhos utilizam materiais como matapi, caniço, malhadeira e anzol. O matapi é uma armadilha tradicional de captura do camarão e é feito com talas de palmeira. Esta atividade é realizada em sua maioria pelas mulheres. 
Segundo as pescadoras, a fase da lua minguante é o momento de iniciar a jornada da pesca do camarão. Essa jornada obedece a um ritual. Primeiro são coletadas as folhas e fibras de espécies como arumã, cupuçuarana e cacau para a confecção da isca, unida com o babaçu. Após essa fase, elas preparam os matapis, amarrando-os num fio, um a um. A quantidade de matapis é variada, pois depende da área de manejo e da quantidade de armadilhas que cada pescadora possui. Após uma semana elas trocam esse instrumento de lugar. De 06 em 06h, as pescadoras, com suas canoas, vão até o local das armadilhas para retirar os camarões que são colocados em uma caixa feita de madeira e tela, denominada por elas de viveiro. Quem fabrica os viveiros são os homens. Estes ajudam as mulheres carregando esse equipamento pesado para a água.

Antigamente as mulheres dependiam dos maridos para obterem os matapis, visto que eram eles que administravam os recursos financeiros da família. Além disso, após a pesca, o camarão era repassado a eles para ser comercializado em Mazagão Velho ou Santana. A dependência das pescadoras aos homens teve fim após a criação da Ampafoz. Por meio de parcerias, a associação promoveu a inserção das mulheres na atividade extrativista, de modo que elas tivessem acesso à renda obtida com a venda do produto. Para isso, alcançaram financiamento do Fundo Nacional do Meio Ambiente para a construção de uma sede, matapis e realização de cursos sobre práticas na produção. As mulheres fizeram cursos diversos para aumentar a produtividade, receberam os matapis e agora ajudam os maridos a complementar a renda familiar. Mensalmente a produção de cada pescadora rende cerca de $60 \mathrm{~kg}$. O preço do quilo varia entre $R$ \$ 5,00 e $R$ \$ 6,00, alcançando uma quantia relativamente baixa, mas essencial para que as pescadoras tenham a autoestima reforçada.

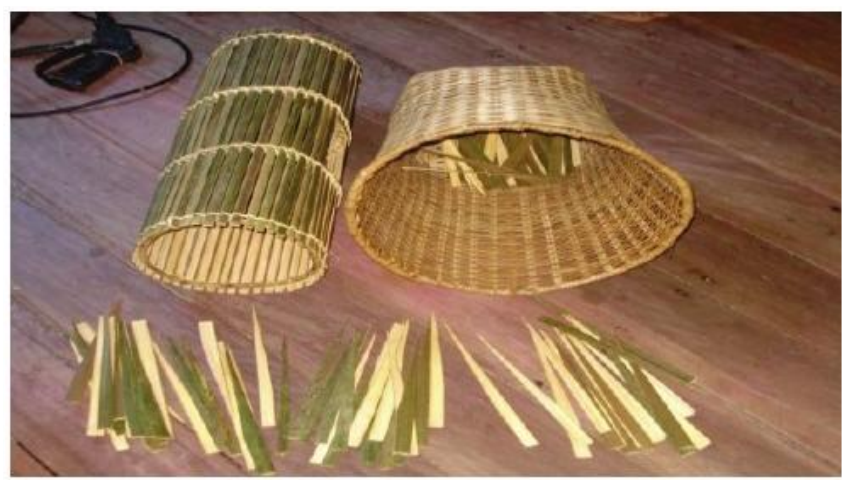

Figura 7: matapi, peneira e talos de palmeira para a confecção do matapi, armadilha de captura do camarão. Org: Lomba e Fonseca, 2011

A pesca do peixe é realizada, em sua maioria, pelos homens. Eles utilizam a malhadeira, tarrafa, linha e anzol. Para isso, cercam uma área para colocar a malhadeira 
e de hora em hora verificam se há peixe. Em cada verificação eles retiram os peixes e colocam em baldes. A venda do produto é feita para funcionários públicos que trabalham no local ou na vila de Mazagão Velho. O preço varia entre $R \$ 3,00$ a $R$ \$ 5,00 .

O açaí é outra atividade que se destaca na comunidade. É visível a existência de extensas áreas contendo a palmeira. Há seis anos, os moradores vêm desenvolvendo o manejo do açaí. A Aaflomaza recorreu à Embrapa para oferecer cursos sobre o manejo do produto, pois, ao passar o período da safra a renda dos moradores ficava comprometida. Com o manejo, a açaí produz o ano todo, realizado especialmente pelas manhãs. Para isso, eles utilizam técnicas tradicionais dos caboclos da Amazônia: escalam o açaizeiro com auxílio de peçonha e terçado. Após a colheita, eles fazem a debulha e a colheita dos caroços colocando em cestos de fibras de vegetais.

Nesta atividade envolvem-se homens, mulheres e crianças. A venda do produto é feito na própria residência do ribeirinho ou no município de Santana. Nos dois locais o produto é entregue ao atravessador que na prática, determina o preço da mercadoria. A atuação da Aaflomaza vem realizando esforços para assinar convênios com indústrias ou cooperativas em Macapá e Santana com fins de eliminar a dependência do atravessador. O preço do açaí na safra varia entre R \$ 40,00 a 50,00 o cesto com $50 \mathrm{~kg}$. Próximo do final da safra, $\mathrm{R} \$ 60,00$ a 70,00. Na entressafra $\mathrm{R} \$ 65,00$ a 75,00 .

Dentre as atividades extrativistas, a atividade madeireira é executada em menor proporção. No ano de 2003, havia 15 serrarias e hoje, apenas três. Em 2006, houve intenso controle pelo Batalhão Ambiental e isso resultou em conflitos entre os moradores e os representantes do órgão. Os moradores não cumpriam as normas ambientais, realizando o extrativismo predatório. Quando começaram a perceber o esgotamento desse recurso natural, iniciaram formas mais adequadas de exploração. A exploração desordenada da madeira resultou no aumento de áreas alteradas e na redução dos estoques madeireiros.

Algumas famílias desenvolvem atividades agrícolas para subsistência e comércio de excedentes. Nessas propriedades encontram-se plantações de banana, milho, limão, cana, macaxeira, coco, cupuaçu, manga e goiabaraçá. Muitos moradores constroem hortas nos trapiches das residências onde são produzidas verduras e leguminosas, entre as quais: pimenta de cheiro, coentro, cheiro verde, chicória, couve, pimentão e tomate. Os moradores fazem polpa para venda da produção de alguns frutos, como o cupuaçu e goiabaraçá. As mulheres embalam em sacos de $1 \mathrm{~kg}$ e vendem para produtores de Santana e Mazagão e, ainda, para a escola da comunidade que utiliza na merenda escolar.

Cada quilo de polpa vale $\mathrm{R} \$ 5,00$ e cada produtor consegue, em média, $\mathrm{R} \$$ 500,00 a 700,00 por safra desses produtos. Registramos em menor dimensão a criação de animais para venda e consumo dos moradores, como porcos, galinhas e patos 
criados nos quintais das casas. É uma atividade direcionada quase exclusivamente para subsistência, sendo rara a venda das aves, que ocorre especialmente no mês de dezembro.

Todas as atividades descritas acima contribuem para a sustentabilidade socioeconômica dos ribeirinhos. A partir da venda de algum excedente, eles têm acesso aos produtos manufaturados, bens materiais, e outros. Contudo, é importante ressaltar que benefícios como o Bolsa-Família, Bolsa Cidadã, Seguro Defeso e aposentadorias contribuem para as rendas das famílias (em geral, pobres). Outros moradores são trabalhadores assalariados ou diaristas, trabalhando especialmente como domésticas nas residências daqueles que possuem maior poder aquisitivo, na escola da comunidade como merendeira, servente, vigilante, catraieiro e professor.

\section{Problemas e dilemas na comunidade Foz do Rio Mazagão}

Foz de Mazagão enfrenta problemas de toda ordem. No que diz respeito ao escoamento da produção, segundo os residentes, o primeiro impasse é a dependência da venda dos produtos para o atravessador, pois, os produtores têm dificuldades de levar seus produtos para a venda em outros mercados, como na cidade de Santana. O principal problema é que o atravessador determina o preço da mercadoria, em geral, um equivalente que favorece apenas ele. Geralmente, o preço pedido pelo produtor é superior ao que o atravessador está disposto a pagar.

Embora as dificuldades seja uma realidade constante em toda extensão rural do Estado do Amapá, na área em estudo também destacamos problemas sociais, como na área de educação, sendo na comunidade a presença de duas escolas, uma municipal e outra estadual. Segundo os moradores, a Prefeitura Municipal tem se empenhado em oferecer este serviço com qualidade, mas na escola estadual, a situação é pior. A Escola Estadual Leandro Plácido Ferreira está deteriorada, sendo que, em 2010, os alunos precisaram sair do local com urgência, porque a infraestrutura estava fragilizada.

Os alunos foram transferidos para uma sede comunitária, contudo, sem condições adequadas para o desenvolvimento das atividades. Outra dificuldade é a permanência dos professores na comunidade. Segundo os moradores, uma parte dos docentes vem de Macapá ou Santana para trabalhar, mas não se adaptam ao local. Isso é decorrente do fato de estarem acostumados a uma vida mais urbana que rural. Por conta disso há um fluxo grande de professores que iniciam seus trabalhos mas logo retornam para seu lugar de origem. Como consequência, o ano letivo fica comprometido, pois os alunos ficam sem aulas.

Há problemas também na falta de merenda escolar e material de apoio (didático e manutenção). A oferta restrita de apenas uma modalidade de ensino, que contempla as séries iniciais até ao $9^{\text {a }}$ ano do Ensino Fundamental, também aflige os moradores. Para a continuidade dos estudos, os adolescentes precisam se deslocar para zona urbana. Em função dessa problemática, muitos jovens são obrigados a optarem 
entre o trabalho e o estudo, e, apesar de muitos filhos dos ribeirinhos já estarem cursando o nível superior, alguns optam pelo trabalho, pela necessidade imediata. Em 2007, quando a sede comunitária do local foi inaugurada, o Estado se comprometeu com a construção de escolas em Foz de Mazagão e em Mazagão Velho. Na vila, a escola já foi inaugurada e na comunidade Foz do Rio Mazagão não existe obras iniciais, nem previsão. Os moradores se disponibilizaram em ajudar na construção, doando a mão de obra e madeira, como já fizeram outras vezes, mas relatam que o Estado precisa assumir compromisso. No início de 2011, a comunidade acionou os meios de comunicação e mostrou a realidade local. Infelizmente as mobilizações e manifestos da comunidade ainda não surtiram o efeito necessário para melhorar a situação.

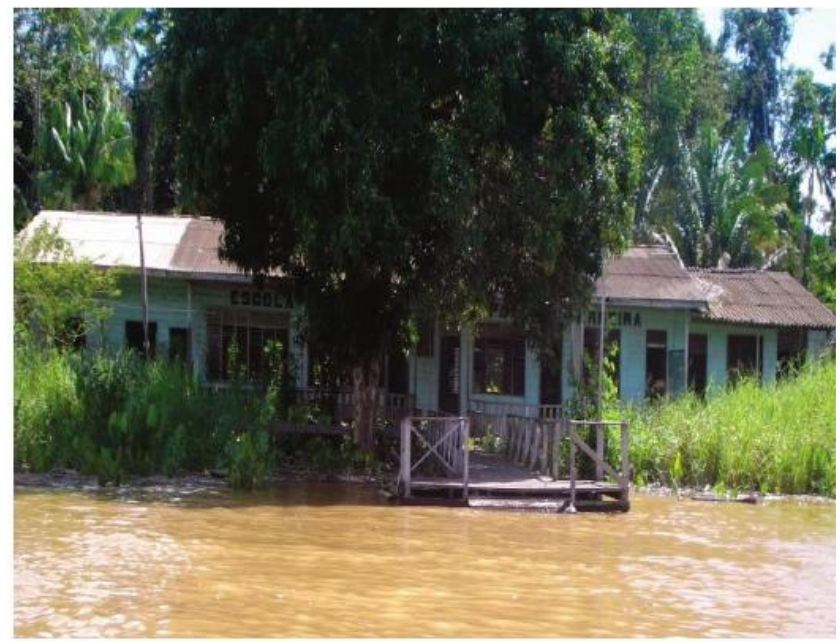

Figura 8: Escola Estadual Leandro Plácido Ferreira.

Org: Lomba e Fonseca, 2011.

No que tange ao acesso à saúde pública na comunidade, as condições sempre foram precárias, não havendo, por exemplo, posto de saúde. A Prefeitura de Mazagão contratou uma técnica em enfermagem como forma de amenizar o problema. Trata-se de uma moradora do local que atende os ribeirinhos utilizando como transporte uma canoa. Ela relata que a Prefeitura envia medicamentos, mas não atende a demanda populacional. Faltam também materiais para curativos. Embora existam postos de saúde em Carvão e Mazagão Velho, eles também funcionam com muitas carências estruturais, profissionais e de medicamentos. A população recorre ao hospital localizado na sede do município de Mazagão, que por não dispor de especialidades médicas encaminha os doentes com casos graves para Macapá ou Santana. O translado dos doentes é outro dilema enfrentado pelos moradores. Não há transporte disponível para isso e nos casos de acidente ou doenças mais graves, os ribeirinhos contam com o apoio dos policiais do Batalhão Ambiental e com moradores que possuem voadeiras. 
Outro problema também é a quantidade de produtos (hipoclorito de sódio e dióxido de cloro) entregues pela empresa de abastecimento de água, Caesa, aos moradores para o tratamento. Segundo eles, é um percentual muito reduzido, o que os obrigam a comprarem maiores quantias para garantir a qualidade da água. $\mathrm{Na}$ ausência do produto, são frequentes os casos de diarreia, infecção intestinal, doenças na pele e outros.

No inverno, os moradores ficam vulneráveis à malária, visto que, segundo eles, neste período aumenta a quantidade de mosquitos. O acesso à energia elétrica, apesar de o sistema atender a todos, o serviço ainda é precário, pois foram os próprios moradores quem fizeram a instalação elétrica em suas casas, utilizando fios sem qualidade para isso.

No aspecto da segurança pública, há policiais do Batalhão Ambiental trabalhando na área, porém não existe uma base da Polícia Militar. Uma moradora cedeu uma de suas residências para que policiais ficassem instalados, contudo, segundo os mesmos, uma base precisa ser estruturada com equipamentos de segurança. Os policiais relatam que, na comunidade, o índice de ocorrências é bem reduzido e que são mais frequentes os crimes ambientais. Quando ocorrem fatos fora da normalidade, como brigas, destacam a necessidade de algemar o infrator numa árvore de açaí ou então, transferi-lo para a Vila de Mazagão Velho.

Apesar das dificuldades, os moradores desenvolveram, ao longo dos anos, uma maneira de organizar a produção e bens necessários à sobrevivência. Com isso, podemos dizer que eles criaram um modo de vida particular, mas se considerarmos sua originalidade, perceberemos constantes mudanças na organização dos moradores. Essa dinâmica surge a partir do momento em que eles começam a superar a condição de pobreza a qual estavam submetidos no aviamento e até certo período da atividade madeireira e passam a administrar seus empreendimentos, possibilitando o acesso a produtos e bens mais comuns na cidade.

O contato com o mercado permitiu a relação com outras culturas. Eles aderiram parte disso e aplicaram no seu modo de vida, como a produção de vinho do açaí, agora realizado em escala maior e mecanizado. Eles consomem novos produtos como eletrodomésticos que permitem o acesso às informações e que garantem conforto, contudo, sem deixar as maneiras tradicionais do modo de vida do passado. A existência do fogão à lenha nas residências e das redes, a utilização das técnicas primitivas para pescar e caçar vem demonstrar a manutenção desse modo tradicional de vida.

Parte dessas mudanças contribuiu para que os ribeirinhos mudassem sua condição de subdesenvolvimento. Isso não repercutiu apenas na área econômica, mas também na educação dos filhos dos ribeirinhos e nas mudanças de comportamento. Com a ampliação da educação escolar já se observam ribeirinhos cursando o nível superior e outros que já o concluíram. Os ribeirinhos também adquiriram noções sobre 
formas de organizações sociais e criaram suas associações na reivindicação por seus direitos

Por fim, podemos afirmar que Foz de Mazagão é uma comunidade que desenvolve um modo de vida mais independente do capital. E mesmo o capital possibilitando o acesso a meios de sobrevivência parecidos com aqueles que se desenvolvem no meio urbano, ele não extinguiu totalmente a maneira tradicional de viver dos ribeirinhos. Ao contrário, eles também aproveitaram os fatos para sair da marginalidade. E apesar da comunidade enfrentar problemas sociais referentes à educação, à saúde, à infraestrutura e ainda no escoamento da produção, podemos afirmar que a iniciativa dos moradores em superar as dificuldades que surgem nos mais variados aspectos da vida ribeirinha, eles já reconhecem seus direitos e lutam, de forma mais organizadas, por melhorias e qualidade de vida.

\section{Considerações finais}

Analisamos o conceito de modo de vida e como o mesmo pode ser interpretado para a compreensão do sujeito ribeirinho em uma comunidade amazônica. As assimetrias que envolvem a produção do espaço amazônico é algo singular. Considerar a temporalidade do lugar, portanto, é vital.

A formação desse modo de vida é fundamental para compreendermos o ribeirinho da Amazônia. As atividades econômicas que surgiram na região só conseguiram algum êxito a partir da integração do extrativismo como o caso da borracha, madeira etc, incorporados por médios capitais que realizam o aviamento junto a outras atividades praticadas pelo ribeirinho, como a pesca.

Atualmente, a comunidade em estudo, Foz do io Mazagão, sobreviveu a toda sorte de adversidades socioeconômicas, conseguiu se libertar em parte da dependência frente a atravessadores, organizou politicamente por meio de associações e, com isso, teve acesso a políticas públicas, financiamentos subsidiados etc, que, melhoraram em parte as condições de vida locais, permitindo acesso ao consumo de bens e serviços.

Ainda nos dias atuais, quando retomamos a discussão sobre modo de vida ribeirinho, é fato compreender as distâncias geográficas que ainda acometem esse povo, fato que dificultam melhores condições ao acesso à educação, à saúde, ao saneamento básico, à energia elétrica entre outros elementos necessários à vida humana. Essas carências são facilmente verificadas nas comunidades ribeirinhas que, por outro lado, vem sendo reivindicada pelos moradores para minimizar os problemas, como acesso elementar para melhorias de suas vidas e perspectivas mais adequadas para as novas gerações.

\section{Referências bibliográficas}

CARLOS, Ana Fani Alessandri. A (Re) Produção do Espaço Urbano. São Paulo: EDUSP, 1994. 
GONÇALVES, Carlos Walter Porto. Amazônia, Amazônias. São Paulo: Contexto, 2001.

LA BLACHE, Paul Vidal de. Geografia geral - Os genêros de vida na Geografia Humana. Revista Geographia. Rio de Janeiro, v. 7, n. 13, p.113-130, 2005.

MARQUES, Marta Inez Medeiros. O modo de vida camponês sertanejo e sua territorialidade no tempo das grandes fazendas e nos dias de hoje em Ribeira -PB. São Paulo, 1994. Dissertação (mestrado em geografia), Faculdade de Filosofia, Letras e Ciências Humanas. Universidade de São Paulo, 1994.

MORAES. Antônio. Geografia: pequena história crítica. São Paulo: Hucitec, 1994.

RABELO, Benedito Vitor. Mazagão: realidade que devem ser conhecidas. Macapá: IEPA, 2005.

SORRE, Max. A geografia humana. Revista Geographia. Rio de Janeiro, v. 5, n. 10, p.137-143, 2003.

STEWARD, Ângela. Povoamento inicial de Carvão e Mutuacá. Nova Iorque, 2008.

SUZUKI, Júlio Cézar. De povoado a cidade: A transição do rural ao urbano em Rondonópolis. 1996. Dissertação (mestrado em geografia) Faculdade de Filosofia, Letras e Ciências Humanas. Universidade de São Paulo,1996.

VIDAL, Laurent. Mazagão: a cidade que atravessou o Atlântico. São Paulo: Martins Fontes, 2008.

\section{Roni Mayer Lomba}

Graduado e Mestre em Geografia pela Universidade Federal do Mato Grosso do Sul, Doutor em Geografia Humana pela USP. Professor Adjunto da Universidade Federal do Amapá. Professor Permanente do Mestrado em Desenvolvimento Regional da Universidade Federal do Amapá. Endereço: Colegiado de Geografia, Rod, JK, km 02, Jd Marco Zero do Equador, Macapá-AP, CEP: 68903-419. Email: ronimayer@hotmail.com

\section{Meg Briane da Silva Fonseca}

Graduada em Geografia pela Universidade Federal do Amapá. Professora da rede estadual pública de ensino do Amapá. Endereço: Colegiado de Geografia, Rod, JK, km 02, Jd Marco Zero do Equador, Macapá-AP, CEP: 68903-419. Email: megfonseca2010@hotmail.com

Recebido para publicação em maio de 2015 Aprovado para publicação em novembro de 2015 